\title{
Comparative study of the Tesla Model S and Audi e-Tron Induction Motors
}

\author{
Robin THOMAS*, Hugo HUSSON*, Lauric GARBUIO* and Laurent GERBAUD* \\ * Univ. Grenoble Alpes, CNRS, Grenoble INP1, G2Elab F-38000 Grenoble, France, \\ e-mail: robin.thomas@g2elab.grenoble-inp.fr, hugo.husson@grenoble-inp.org \\ lauric.garbuio@g2elab.grenoble-inp.fr, laurent.gerbaud@g2elab.grenoble-inp.fr
}

\begin{abstract}
Tesla and Audi are two of the most iconic representative of the premium electric vehicles on the market. For their flagship vehicles, the Tesla Model S/X and the Audi e-Tron, the two manufacturers made the same choice to use squirrel cage induction machines. Thus, the paper presents a retro-engineering study of these two motors in order to compare the design strategies made by Tesla and Audi. This comparison is based on two main aspects. The technical design of the two induction motors are firstly compared. Then, the two motors output performances are computed. This study is based on the simulation results of the 2D finite element models of the each machine. Finally, an analysis of the different strategies deployed by the two manufacturers, between technological innovation and cost reduction, is proposed.
\end{abstract}

Keywords—electric vehicle, squirrel cage induction motor, reverse engineering, Tesla Model S, Audi e-Tron

\section{INTRODUCTION}

From all the electrical car manufacturers, Tesla and Audi are among the most iconic representative of the premium electric vehicles on the market. Their flagship vehicle, the Tesla Model S/X and the Audi e-Tron, are two of the most sold electric cars of the E/F-SUVs segments (Fullsize) [1] in 2020. Moreover, these two vehicles present similar drivetrains, even if the power rating is not the same. Both manufacturers made the less common choice to use squirrel cage induction machines (SQIM) in a dual motor configurations, or even tri-motor for some Audi models. Indeed, this is not the most common technical choice in the electrical car market as permanent magnet synchronous machines (PMSM) often have higher efficiency and higher powerto-weight ratio [2] even though SQIM are generally easier to build, cheaper and more robust. Moreover, the two manufacturers created similar motor design with deep rotor bars and bridges to close the rotor slots. Beyond these common features, Audi and Tesla engineers made also several different design choices for the SQIM. Indeed, a different material is used in the squirrel cage, the cooling system is not the same, etc. This leads to different performances.

Thus, the paper aims to compare the design and the related performances of these two machines. In order to do that, the technical choices made by each manufacturers are firstly compared. Then, the performances in terms of efficiency, loss distribution and control strategy are compared using the approximate 2D finite element (FE) models of these two machines [3]. Finally, an analysis of the impact of these different technical choices on the performances is proposed.

\section{MethodOLOGY}

\section{A. Comparison Method}

The comparison between the performances of these two motors is based on the simulation results from their approximate 2D finite element models [3]. The aim is to highlight the differences and the impact of the different technical choices on the performances of the machine. These two models are made using Altair Flux2D ${ }^{\mathrm{TM}}$ and Altair FluxMotor ${ }^{\mathrm{TM}}$ softwares.

As the two machines have different power ratings, the performance comparison is mainly made on adimensional quantities, such as the efficiency or the loss distribution between the stator and the rotor. The assumed control strategy is also studied: the values of the imposed voltage and slip in order to reach the studied operating points as well as the related efficiency are compared.

\section{B. 2D Finite Element Models of the Tesla Model S and Audi e-Tron Induction Motors}

The studied machine for Tesla is the rear motor of the Tesla Model S 60. However, it is also the rear machine of the Tesla Model X, Tesla's SUV, as the two vehicles share around 30\% of their components [4]. For Audi, the e-Tron 55 Quattro SUV has two induction motor types, the APA250 at the front axle and the AKA320 at the rear axle [5]. The motor that is considered in the paper is the AKA320.

\footnotetext{
${ }^{1}$ Institute of Engineering Univ. Grenoble Alpes
} 
The two 2D FE models that are used to simulate and analyse these motors were made from all the information found in the scientific literature, in patents, in official manufacturer data or online. Then, they were simulated and validated by comparing the obtained results with the official performances. The final induction machine models that are used are shown in Fig. 1. Several uncertainties remain on some of the geometrical dimensions or on the material properties, impacting directly the resulting performances, but the validation process enabled to prove that these models represent the global behaviour of each machine with sufficient accuracy to be used to carry out retro-engineering studies like the one presented in the paper.

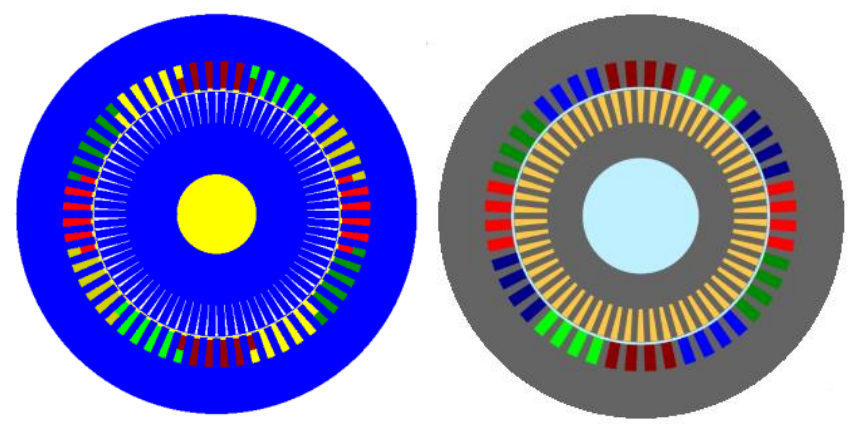

Fig. 1. 2D FE model of the Tesla Model S60 SQIM (left) and of the Audi eTron SQIM (right) [3] made with Altair softwares.

\section{Simulation Hypotheses}

These models were defined with the following hypotheses:

- only active parts are considered;

- no mechanical losses are taken into account;

- the operating temperature is imposed at a constant value throughout the machine. This value corresponds to the assumed temperature under rated operating conditions for the two motors.

For the simulation conditions, the following hypotheses are taken:

- the simulations are running under steady-state AC magnetic conditions, i.e. sinusoidal steady state at a given frequency. The material relative permeability is also linearized around the studied operating point to consider saturation level;

- the simulations are parameterized in order to study how the motor output performances vary according to slip;

- the motor is fed by a three-phase balanced voltage source;

- the stator and the rotor Joule losses are considered as well as the iron losses.

\section{DESIGN COMPARISON}

\section{A. General data}

Tesla and Audi engineers decided to use a four poles squirrel cage induction machine for their vehicle with a similar design and a comparable size whereas the power rating is very different. The main maximal performance ratings are shown in Table I.

table I. Maximal Performance Ratings of the Tesla Model S/X and the Audi e-Tron Induction Motors [6], [7], [8], [9]

\begin{tabular}{|c|c|c|}
\hline Parameters & Tesla Model S/X & Audi e-Tron \\
\hline Output Power & $225 \mathrm{~kW}$ & $140 \mathrm{~kW}$ \\
\hline Torque & $430 \mathrm{Nm}$ & $314 \mathrm{Nm}$ \\
\hline Rotating Speed & $15,000 \mathrm{rpm}$ & $15,000 \mathrm{rpm}$ \\
\hline Battery Voltage & $366 \mathrm{~V}$ & $396 \mathrm{~V}$ \\
\hline $\begin{array}{c}\text { RMS Phase-to-neutral } \\
\text { Voltage }\end{array}$ & $150 \mathrm{~V}$ & $208 \mathrm{~V}$ \\
\hline RMS Line Current & $900 \mathrm{~A}$ (peak) & $\begin{array}{c}240 \mathrm{~A} \\
\text { (continuous) }\end{array}$ \\
\cline { 3 - 3 } & $480 \mathrm{~A}$ (peak) \\
\hline \multirow{2}{*}{\begin{tabular}{c}
$530 \mathrm{~A}$ (boost) \\
\hline
\end{tabular}}
\end{tabular}

The voltage limitations are computed from the battery voltage, considering a space vector pulse width modulation control of the inverter. However, the rated line-to-line voltage of the Audi machine is announced at $360 \mathrm{~V}$ even though the battery voltage is only $396 \mathrm{~V}$ [8], [9]. On the other hand, several maximum rms currents are given, depending on the operating mode that is considered. Indeed, Audi describes in its official data three different operating modes depending on the time considered: continuous performance, peak performance during $60 \mathrm{sec}$. and boost performance during $10 \mathrm{sec}$. [8].

Thus, a first element of comparison can be noted here. Indeed, it seems that Tesla made the choice to design a low voltage - high current machine while Audi chose a more balanced compromise. Therefore, Tesla's choice implies to provide a very efficient cooling system, which will be discussed in the following. 


\section{B. Geometry}

As it has been said, the two machines have a similar design with similar 2D dimensions. Table II shows the main global dimensions of the two machines. It can be seen that the size of the rotor is the same but the air gap is slightly larger for the eTron motor with a smaller stator yoke too. The main difference that can be observed is the total length of the active part of the machine. Indeed, the e-Tron motor is almost $40 \%$ longer than the Tesla SQIM, leading to a global volume of the active parts that is almost $30 \%$ bigger while the rated power is also almost $40 \%$ lower. This leads to a peak power to volume ratio for Tesla that is more than twice that of Audi.

TABLE II. Main Geometrical Dimensions of the Tesla Model S/X AND the Audi E-Tron InduCtion Motors [3], [7], [8], [10], [11]

\begin{tabular}{|c|c|c|}
\hline Parameters & Tesla Model S/X & Audi e-Tron \\
\hline Stator Outer Diameter & $254 \mathrm{~mm}$ & $245 \mathrm{~mm}$ \\
\hline Stator Inner Diameter & $156.8 \mathrm{~mm}$ & $157.2 \mathrm{~mm}$ \\
\hline Air gap & $0.5 \mathrm{~mm}$ & $0.6 \mathrm{~mm}$ \\
\hline Rotor Outer Diameter & $155.8 \mathrm{~mm}$ & $156 \mathrm{~mm}$ \\
\hline Rotor Inner Diameter & $50 \mathrm{~mm}$ & $70 \mathrm{~mm}$ \\
\hline Stack length & $152 \mathrm{~mm}$ & $210 \mathrm{~mm}$ \\
\hline Active parts volume & $7.7 \mathrm{~L}$ & $9.9 \mathrm{~L}$ \\
\hline Peak power-to-volume ratio & $29.2 \mathrm{~kW} / \mathrm{L}$ & $14.1 \mathrm{~kW} / \mathrm{L}$ \\
\hline
\end{tabular}

Regarding the stator slots and the rotor bars, their shape is also very similar. The Audi e-Tron SQIM has 48 stator slots and 58 rotor bars while the Tesla machine has 60 stator slots and 74 rotor bars [3], [6], [8]. These combinations satisfy the basic design rules that enable to avoid the potential harmful slot harmonics or mechanical vibrations [12], [13]. Thus, their selection could be linked to a torque ripple minimization study. Moreover, since the global dimensions are alike, this means that the stator slots and the rotor bars are larger in Audi's SQIM. As the materials used are different between the two machines, this design choice can be explained by a will to reduce the rotor resistance for Audi, as it will be discussed more precisely in the following. On the other hand, the two manufacturers made the choice to use deep rotor bars and to close them with thin rotor bridges [3], [7], [8]. This choice enables to smooth the air gap flux density distribution and to reduce the electromagnetic noise, the vibrations and the torque ripple.

As it can be observed, the two machines present very similar 2D design with comparable design choices. However, Audi's motor is bigger than Tesla's SQIM. This difference could be explained by the fact that Audi made the choice to develop axle drive kits that share a large amount of components to reduce costs and save time during the manufacturing process. Thus, all the different Audi e-Tron line-up motors are based on the same 2D design and only differ by their active length [8]. On the contrary, Tesla decided to develop specific machines for each vehicles, sometimes even changing the motor topology. It can be seen that the two manufacturers have chosen different strategies, leading to different technical compromises.

\section{Materials}

The electrical steel used in both machines is one of the main uncertainty point. For the modelling of the Tesla motor, M25035A non-grain oriented electrical steel sheets are used due to their high magnetic performances since it is assumed that the real electrical steel would present similar characteristics [3]. For the Audi e-Tron machine, the only information given by Audi is the size of the sheet: $0.35 \mathrm{~mm}$. [8]. Thus, for the same reason than before, similar electrical steel is used in the FE model.

However, the main difference between the two motors is the material used to build the squirrel cage. Indeed, Tesla uses a pure copper squirrel cage while it is made up of pure aluminium for the e-Tron [3], [6], [8]. This technical choice is determinant for induction machines as the rotor resistance has a major impact on the machine performances. A lower resistivity of the squirrel cage enables to reduce the rotor Joule losses and to increase the induced currents, leading to a higher torque and a lower rotor temperature, which is one of the main operating limitations for induction machines [14], [15]. However, the rotor manufacturing method is more complicated and expensive as copper melts at a higher temperature than aluminum, which implies to operate at higher temperatures and pressures to make the cage [14], [15]. This explains why this design choice is not very widespread among manufacturers, even though copper die-casting methods are improving. This different material choice could explain Audi's larger rotor bars, in order to reduce the rotor resistance and the rotor losses. Yet, induction machines with copper rotor remain more efficient than the ones with aluminum squirrel cage. This impact will be studied in the following sections of the paper.

\section{Windings}

The winding configuration that is assumed to be the one of the Model S/X motor from Tesla patents [3], [16] consists of a double layer concentric set of three coils per pole and per phase with a coil pitch of 10-12-14 and turns per coil of 1-2-2 [3], [6]. The conductors are composed of 26 stranded round wires with a diameter of $1.08 \mathrm{~mm}$ [3], [6].

Audi engineers seem to have chosen a more common winding pattern that consists of a single layer distributed set of 2 coils per pole and per phase with a coil pitch of 10 and 6 turns per coil [10]. The conductors are composed of 20 stranded round wires with a diameter of approximately $1 \mathrm{~mm}[10]$. 
The winding factor is computed for the two different motors and it appears that the two different winding configurations give similar values, with a slightly better result for Audi's configuration: $k_{w_{\text {Audi }}}=0.957 / k_{w_{\text {Tesla }}}=0.952$ [7], [17]. Despite this, Tesla made the choice to use their own winding diagram that is less common and simple than Audi's one.

\section{E. Cooling Systems}

The cooling system has a determinant impact on induction machine performances. Indeed, this cooling efficiency will enable to set the main operating limitations but it will also affect the materials properties, especially for the rotor cage. In induction motors, the temperature of the rotor is critical since the produced Joule losses are highly dependent on the slip and the material resistivity, leading to degraded performance. This is why the two manufacturers have given a lot of effort into developing a complex cooling system including stator and rotor cooling.

Tesla built a cooling system with two main parts: a classical cooling jacket at the stator and an innovative spiral shaft groove as it can be seen in Fig. 2. [3], [6]. These two systems are fed in parallel with cooling fluid and the pipes are then connected to the power electronics and to the gear box cooling units [18]. Thus, the stator and the rotor are cooled with a cold fluid that is directly coming from the heat exchanger.

On the other hand, Audi engineers made the choice to develop a slightly more complex cooling system, based on a combination of water and convection cooling [8]. In their system, the coolant firstly flows through the power electronics, then through the stator cooling jacket, through the bearings and finally through the interior of the rotor shaft as it can be seen in Fig. 3 [8]. Thus, all the different parts of the motor cooling system are connected in series, leading to a higher coolant temperature inside the rotor shaft than inside the stator. However, fan blades are also built on the rotor to improve the rotor cage rings and the stator windings heads cooling [8]. This shows that the rotor is doubly cooled, internally and externally to ensure the best continuous performance, durability and reproducibility [8].

\section{F. Summary}

To conclude this first theoretical study on the comparison of the design of these two machines, it can be seen that Tesla and Audi chose two different strategies. On one hand, Tesla chose to develop the most optimized machine to reach the highest possible performances even if the related cost can be sometimes higher, especially regarding the materials choice. They developed innovative windings or cooling systems to reach these performances. The designed motors are dedicated to specific drivetrains and for the dual motor vehicles, the two machines have different designs, sometimes even different topologies. On the other hand, Audi chose another compromise. They seem to have placed more emphasis on simplicity of design, sharing of components between machine versions and cost optimisation. This choice has several manufacturing advantages but may lead to lower efficiency since all their machines only differ by their length or are made with aluminium squirrel cage, explaining why they needed to develop a more complex cooling system.

The impact of these two different strategies on the performances is discussed in the next section.

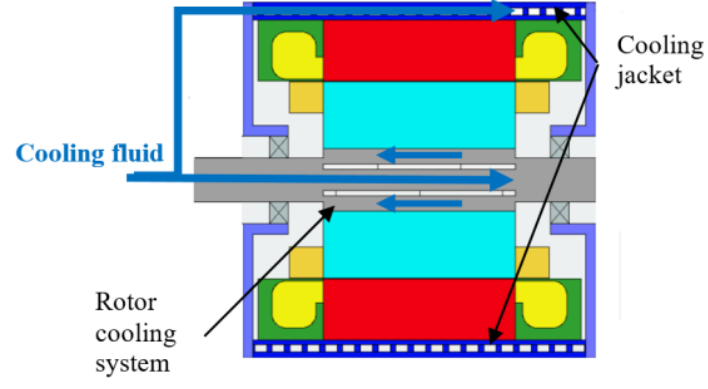

Fig. 2. Tesla Model S/X induction motor cross-section with representation of the cooling system [3], [19]

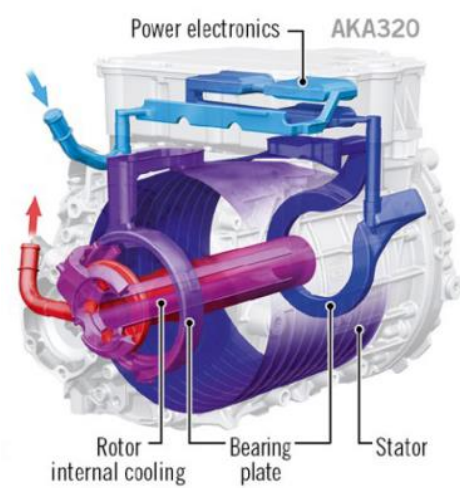

Fig. 3. Cooling concept of the AKA320 electric axle drives with power electronics cooling, stator, end shield and rotor internal cooling [8].

\section{PERFORMANCE COMPARISON}

In order to have a complete view of the evolution of the two machines performances depending on the operating point, several efficiency maps have to be drawn. To do this, a large amount of (voltage, frequency, slip) combinations are simulated. The resulting simulated operating points are placed in the (rotating speed, torque) system of axes and for similar output performances, only the points with the highest efficiency are considered. Indeed, with an induction machine, there are many possibilities to reach one operating point, depending on the voltage, current, frequency and slip. This is why only the optimal operating points are kept to draw the efficiency map.

Obviously, the shape of the isovalue boundaries of these maps is directly linked to the amount of FE simulations that are carried out. However, considering the simulation times, this method enables to draw sufficiently precise maps to carry out the retro-engineering study within an acceptable time. 


\section{A. Efficiency maps}

To highlight the performances of these two machines, the main comparison point is the efficiency. Thus, it is found that at their maximum output power and rated rotating speed operating point, the Audi e-Tron has a lower efficiency, 92\%, than the Tesla Model S, 93.4\% [3].

The efficiency maps of the Tesla Model S60 and the Audi e-Tron are presented in Fig. 4. and Fig. 5. Firstly, it can be seen that both machines present similar efficiency maps. However, it can be observed that in fact the range in which the Tesla motor has an efficiency higher than $98 \%$ or even $97 \%$ is much more extended than for the Audi e-Tron. This means that the Tesla machine is more efficient on a wider speed and torque range and especially at high speeds. Indeed, this result was expected since the aluminum cage of the e-Tron motor implies higher losses especially at high frequency due to the skin effect in the bars that are quite large compared to Tesla's bars. On the other hand, the two machines have globally the same efficiency at low rotating speeds.

Thus, for similar operating conditions, the Tesla machine seems to be more efficient than the Audi SQIM.

\section{B. Loss distribution}

The comparison of the loss distribution shows the impact of the design strategy on the machine behaviour. Indeed, depending on the loss location, the performances have a different behaviour and the cooling system has to be different. The loss distribution maps are drawn and are shown on Figs. 6-9.

It can be seen that at the stator and the rotor, the global behaviour of the two machines is similar. Indeed, as the torque increases, the current increases, leading to higher stator losses. However, it can be observed that as the Audi machine works with a lower current, the total stator losses are always much lower than the Tesla motor losses. In the two cases, the iron losses are negligible compared to the Joule losses. At the rotor, as the output power increases and, generally, the slip increases, as the rotor losses increase. However, this time the Audi machine has higher losses than the Tesla IMSQ. This difference seems logical regarding the design choices made by the two manufacturers. An aluminium squirrel cage implies a higher resistance but also a higher slip especially at high output power operating points since it is linked to the value of the rotor resistance. Thus, here it can be highlighted that the Tesla engineers' choice clearly enables to reach higher performance.

Finally, the loss distribution comparison enables to show another main difference. Indeed, thanks to its more efficient copper cage but due to its higher operating current, the Tesla motor loss distribution is divided between one third at the rotor and two thirds at the stator. On the contrary, the e-Tron induction motor losses are divided in two between the stator and the rotor. This ratio is even changing as the output power increases and the rotor losses are getting more predominant. Thus, these results can explain the will of Audi to make a very efficient and complex cooling system to extract heat from the rotor compared to Tesla.

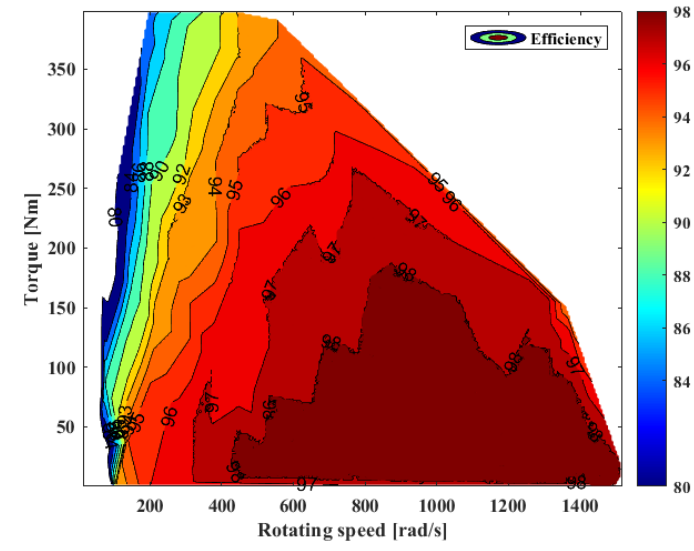

Fig. 4. Tesla Model S60 SQIM FE model efficiency map (considering only stator and rotor Joule losses and iron losses) [3].

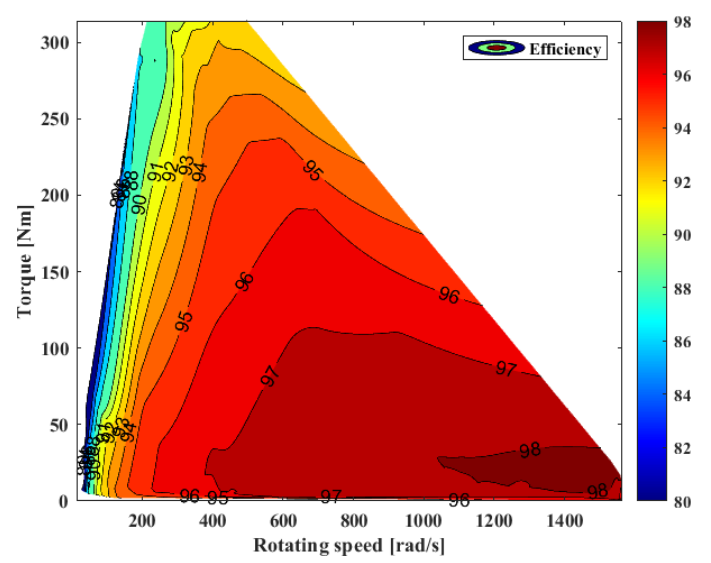

Fig. 5. Audi e-tron SQIM FE model efficiency map (considering only stator and rotor Joule losses and iron losses) 


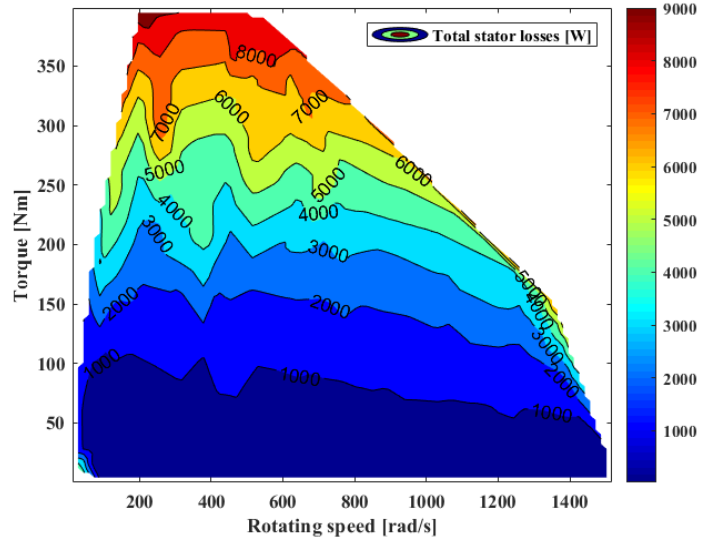

Fig. 6. Tesla Model S60 SQIM FE model total stator losses map (considering Joule losses and iron losses).

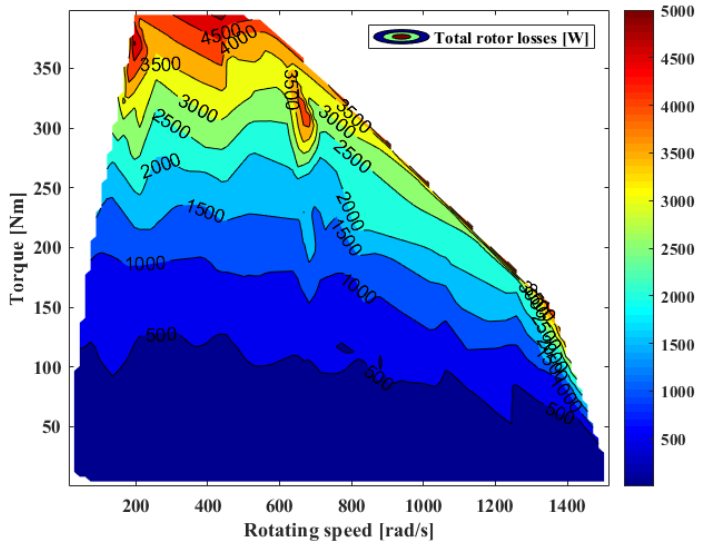

Fig. 8. Tesla Model S60 SQIM FE model total rotor losses map (considering Joule losses and iron losses).

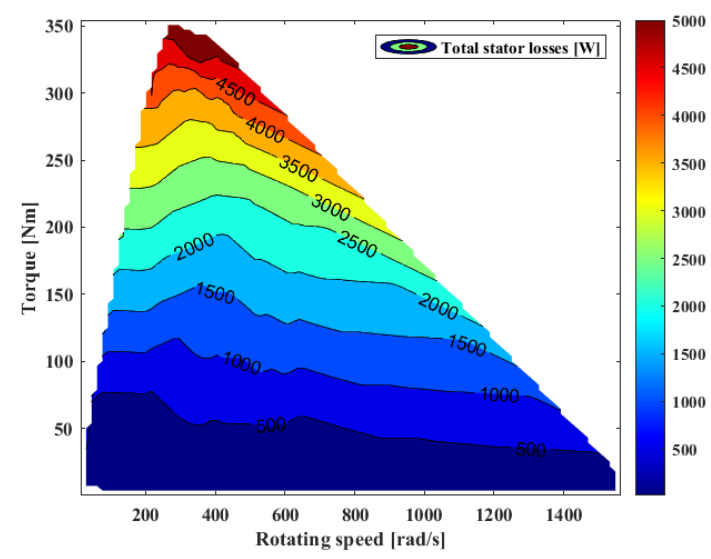

Fig. 7. Audi e-tron SQIM FE model total stator losses map (considering only Joule losses and iron losses).

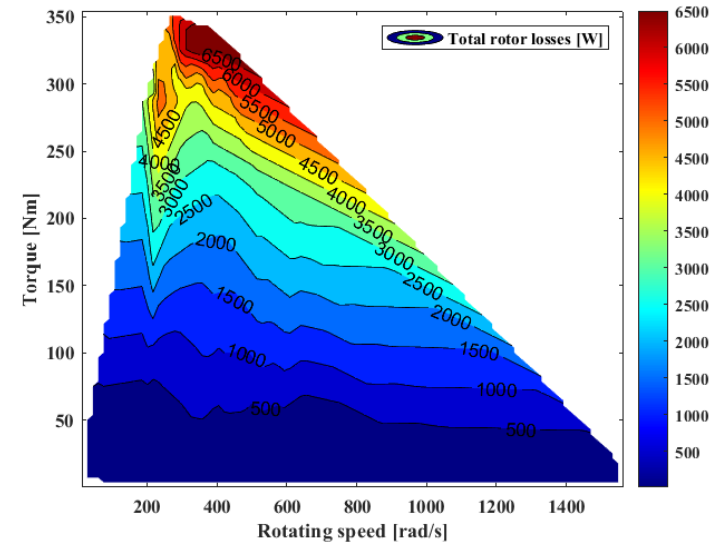

Fig. 9. Audi e-tron SQIM FE model total rotor losses map (considering only Joule losses and iron losses).

\section{CONTROL STRATEGY COMPARISON}

In order to study the assumed control law of the two machines, the slip and stator voltage over frequency (V/f) maps that are related to the presented efficiency maps are computed. The V/f maps are studied because they give a picture of the evolution of the global magnetic flux through each machine. The assumed control technology is field-orientation vector control. Thus, this can give a global overview of the way the machine is controlled in order to reach the maximum possible efficiency and, more precisely, which Joule losses-iron losses balance should be applied to maximize the efficiency. Only the slip maps of the two machines are shown in Fig. 10 and Fig. 11. The slip is always indicated in percent.

The first aspect that can be observed is that the Audi machine is always working with a higher slip whereas the Model S motor. This is directly linked to the rotor resistance and, thus, the material chosen as explained previously. This result can also be related to the previously shown rotor loss maps, since the cage Joule losses are directly proportional to slip. However, despite this observation, both motors have globally a similar behaviour.

The study of the V/f maps show that, in fact, to operate at the highest possible efficiency while respecting the machine operating limitations, a "classical" vector control of the torque and flux could be applied [20]. Indeed, it is observed that from zero to the rated rotating speed, the magnetic flux has to be maintained approximately constant around its rated value, except

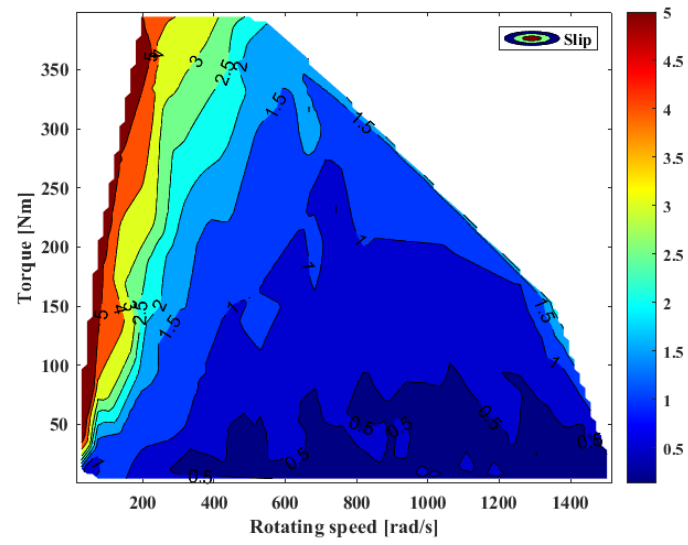

Fig. 10. Tesla Model S60 SQIM FE model slip map related to the efficiency map.

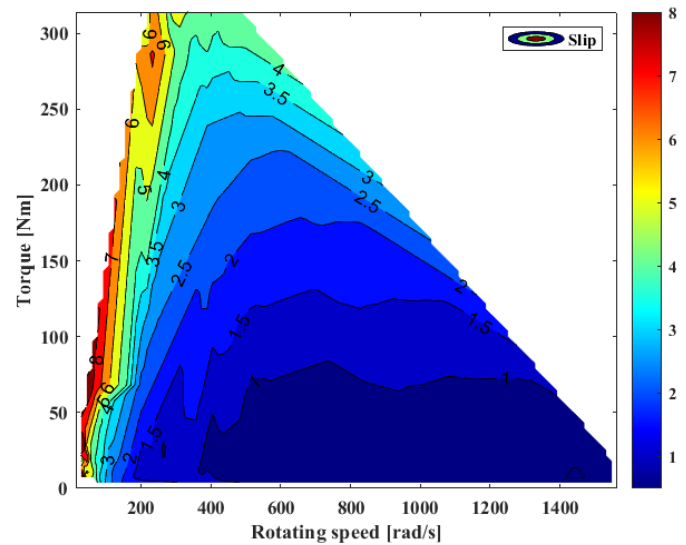

Fig. 11. Audi e-tron SQIM FE model slip map related to the efficiency map. 
for low torque operating points where the flux has to be decreased to reach the highest possible efficiency. Following the induction machine equations, if the flux is maintained constant, the slip increases linearly as long as we operate at the same torque, as it has been observed previously [20]. Then, once the rated speed is reached, a flux-weakening strategy has to be applied and, thus, the slip will remain at an approximately constant value [20], which is also what can be observed in slip and V/f maps. However, little specificities have to be applied depending on the torque level, i.e. especially at low torque, to be sure to always reach the most profitable iron losses - Joule losses compromise.

\section{CONCLUSION}

In order to conclude, a comparison of the induction motors that are used in the two most famous representatives of the premium electric vehicle on the market has been presented in the paper. This study is based on two main parts: a comparison of the two different design choices and a comparison of the motors performances based on the simulation results of the 2D finite element models of each induction machine. It has been shown that the two manufacturers have chosen quite different strategies despite the fact that they are working on a similar application. Indeed, Tesla, a young technologically driven company, chose to build a very well technically optimized machine for their own specifications, using innovative windings and cooling system as well as the materials with the best properties even though these choices certainly lead to higher manufacturing costs. On the contrary, Audi, an experienced manufacturer with global reach, decided to use a more "classical" design strategy, using cheaper materials and even an electrical sheet stacking strategy to adapt the power of the designed machine, in order to reduce the manufacturing costs and be prepared for mass production by achieving economies of scale. As it has been highlighted, these two strategies affect directly the machines performances. Thus, the Tesla motor is finally more powerful, and seems more efficient within a smaller volume than the Audi SQIM.

Future work could enable, firstly, to improve the precision of the used 2D FE models by testing directly real machines. Moreover, this comparison study could be extended to other vehicles and even other motor topologies.

\section{REFERENCES}

[1] J. Pontes, "Global Electric Vehicle Top 20 - EV Sales Report", CleanTechnica, February 4 ${ }^{\text {th }}$, 2021. [Online] Available: https://cleantechnica.com/2021/02/04/global-electric-vehicle-top-20-ev-sales-report/

[2] A.M. Bazzi, "Electric machines and energy storage technologies in EVs and HEVs for over a century", Electric Machines \& Drives Conference (IEMDC) 2013 IEEE International, pp. 212-219, 2013.

[3] R. Thomas, L. Garbuio, L. Gerbaud and H. Chazal, "Modeling and design analysis of the Tesla Model S induction motor," 2020 International Conference on Electrical Machines (ICEM), Gothenburg, Sweden, 2020, pp. 495-501.

[4] J. Riswick, “Tesla Model X vs Model S: What's the Difference?”, Autotrader, July 26th, 2016. [Online] Available : https://www.autotrader.com/car-reviews/tesla-model-X-vs-model-s-whats-the-difference-255734

[5] Audi, "Audi e-Tron", Audi official website [Online] Available: https://www.audi.de/de/brand/de/neuwagen/tron/audi-e-tron/motor.html

[6] M. Popescu, J. Goss, D. A. Staton, D. Hawkins, Y. C. Chong and A. Boglietti, "Electrical Vehicles-Practical Solutions for Power Traction Motor Systems," in IEEE Transactions on Industry Applications, vol. 54, no. 3, pp. 2751-2762, May-June 2018.

[7] H. Koke, "Comparative study of stranded and bar windings in an induction motor for automotive propulsion applications.", M.A.Sc thesis, McMaster University, Hamilton, Ontario, Canada, August 2017.

[8] J. Doerr, T. Attensperger, L. Wittmann and T. Enzinger, "The new electric axle drives form Audi”, Audi AG, Ingolstadt, Germany, 2018

[9] T. Lehner-Ilsanker, "Press Information - The Audi e-tron", Audi MediaCenter, November 2018.

[10] "Electric Engine PRODUCTION - Audi e-tron MOTOR”, YouTube video, 15:20, Posted by “Car \& Performance TV,” October 29, 2019, Available : https://www.youtube.com/watch?v=uWBEPEspbWI

[11] “TECHNOLOGY : 2020 AUDI E-tron 1 Animation \& e-Engine Components”, YouTube video, 18:19, Posted by “Motor.TV”, October 14 2019, Available : https://www.youtube.com/watch?v=fAw7hxc3z0Y

[12] G. Joksimović, E. Levi, A. Kajević, M. Mezzarobba and A. Tessarolo, "Optimal Selection of Rotor Bar Number for Minimizing Torque and Current Pulsations Due to Rotor Slot Harmonics in Three-Phase Cage Induction Motors," in IEEE Access, vol. 8, pp. 228572-228585, 2020

[13] J. Pyrhonen, T. Jokinen and V. Hrabovcova. "Design of rotating electrical machines". John Wiley \& Sons, 2013.

[14] L. Szabó, "A Survey on the Efficiency Improve of Electrical Machines," 2019 26th International Workshop on Electric Drives: Improvement in Efficiency of Electric Drives (IWED), Moscow, Russia, 2019, pp. 1-6.

[15] D. T. Peters, E. F. Brush and J. L. Kirtley, "Die-cast copper rotors as strategy for improving induction motor efficiency," 2007 Electrical Insulation Conference and Electrical Manufacturing Expo, Nashville, TN, United States, 2007, pp. 322-327.

[16] Y.Tang, S-P P.Luan, "Dual layer winding pattern”, U.S. Patent 8,154,166 B2, April 10, 2012

[17] "Emetor - Electric motor winding calculator" [Online]. Available: https://www.emetor.com/windings/

[18] J. D. Kelly, "Understanding Tesla Model S Performance Motor", YouTube video, 46:31, Posted by “Weber State University”, Ferbruary 16, 2021. Available : https://www.youtube.com/watch?v=MQV3D8F6gvw

[19] D. A. Staton and J. Goss, "Open source electric motor models for commercial EV \& Hybrid traction motors.”, presented at Coil Winding, Insulation \& Electrical Manufacturing Exhibition (CWIEME) 2017, Berlin, Germany, June 20-22, 2017

[20] B. De Fornel, "Machines Asynchrones - Alimentation et Caractéristiques", Techniques de l'Ingénieur, August 10, 2004 